\title{
Sustainable business models for wind and solar energy in Romania
}

\author{
Maria Alexandra NICHIFOR
}

\author{
Bucharest University of Economic Studies, Bucharest, Romania
}

\begin{abstract}
Renewable energy has become a crucial element for the business environment as the need for new energy resources and the degree of climate change are increasing. As developed economies strive towards greater progress, sustainable business models are of the essence in order to maintain a balance between the triple bottom line: people, planet and profit. In recent years, European Union countries have installed important capacities of renewable energy, especially wind and solar energy to achieve this purpose. The objective of this article is to make a comparative study between the current sustainable business models implemented in companies that are active in the wind and solar energy sector in Romania. Both sectors underwent tremendous changes in the last two years due to changing support schemes which have had a significant influence on the mechanism of the renewable energy market, as well as on its development. Using the classical Delphi method, based on questionnaires and interviews with experts in the fields of wind and solar energy, this paper offers an overview of the sustainable business models of wind and solar energy companies, both sectors opting for the alternative of selling electricity to trading companies as a main source of revenue until 2013 and as the main future trend until 2020. Furthermore, the participating wind energy companies noted a pessimistic outlook of future investments due to legal instability that made them to reduce their projects in comparison to PV investments, which are expected to continue. The subject of the article is of interest to scientific literature because sustainable business models in wind and photovoltaic energy have been scarcely researched in previous articles and are essential in understanding the activity of the companies in these two fields of renewable energy.
\end{abstract}

Keywords: business model, sustainability, wind energy, solar energy, wind farm turbine.

Please cite the article as follows: Nichifor, M.A. (2015), "Sustainable business models for wind and solar energy in Romania", Management \& Marketing. Challenges for the Knowledge Society, Vol. 10, No. 1, pp. 52-60, DOI: 10.1515/mmcks-2015-0004.

\section{Introduction}

There is a growing focus on business models in the renewable energy literature and practice, and on how to use this concept practically in both business and scientific fields. While the development of renewable energy has become one of the main goals of the Member States of the European Union, the ability to create and adapt one's business model in an ever dynamic and competitive environment is a key point in the survival of companies in today's service markets. Business models play an important role in the development of successful companies, including those in the green energy field.

Renewable energy production accounted for $14.1 \%$ of the gross final energy consumption in 2012. Further progress is expected until the 2020 objective of the European Union will be achieved according to Eurostat. The 2020 objective imposes a $20 \%$ share of renewable energy in the gross final energy consumption for all members of the European Union and 10\% of transport final energy consumption. The two sectors of renewable energy, wind and solar, that are

Correspondence: Maria Nichifor maria_nichifor@ hotmail.com 
investigated in the present article are two of the fastest growing sectors of renewable energy in the European Union. Although these two fields have grown exponentially in the last five years in Romania and in other European states, the main characteristics of their specific business models have been scarcely investigated in the scientific literature. The activities of wind and solar energy companies have been often debated in political and economic discussions without revealing the strategic choices that lie behind the financial achievements and business models of these firms.

The main objective of this article is to investigate the current business models in wind and solar energy companies from Romania. These models contain specific components and revenue strategies depending on the companies' goals, organizational culture and external environment. The second argument of this study is to define a path for future scientific research towards the knowledge regarding specific wind and solar energy business models until 2020.

The present study was based on three assumptions that take into consideration the current legal and renewable energy context:

H1: The most preferred business model strategy in the case of wind and solar energy experts is selling energy to a trading company. This assumption was made based on the fact that trading companies are more willing to negotiate the selling conditions than the traditional regional grid operators.

H2: The future trends of wind energy projects in Romania until 2020 will be on-grid, on-shore projects. This assumption was made under consideration of the geographical and climate conditions of Romania, which do not favour the development of offshore wind parks. The on-grid option was chosen due to the fact that on-grid wind parks receive green certificates for the produced electricity.

H3: The future trends of preferred business strategies in the fields of wind and solar energy in Romania will be selling energy to trading companies and to regional grid operators. The same reason as in the first hypothesis was taken into consideration for the option of selling electricity to trading companies, while regional grid operators will remain an important partner of renewable energy companies.

\section{Business models in the renewable energy field}

Business models are the foundation for successful companies. The importance of business models for the companies' activities is also shown by the fact that they can be the subject of patent as Hedman and Kalling (2003) emphasize. In the last decade different approaches regarding the components of a company's business model were presented in numerous studies (Baden-Fullen, 2010; Johnson et al., 2008; Osterwalder and Pigneur, 2010; Vives and Svejenova, 2011), while the same authors affirmed the importance of value creation as the main element of a business model. 
Baden-Fullen and Morgan (2010) state that a business model "provides a set of generic level descriptors of how a firm organises itself to create and distribute value in a profitable manner" (p. 157). Furthermore, Nair et al. (2013) mention core logic, belief systems, cognitive environment and competencies as structural components of business models which must interact effectively and create value from resources. Other authors have illustrated schemes of the fundamental business model elements. Johnson et al. (2008) summarize similar elements of a business model, as shown in Figure 1.

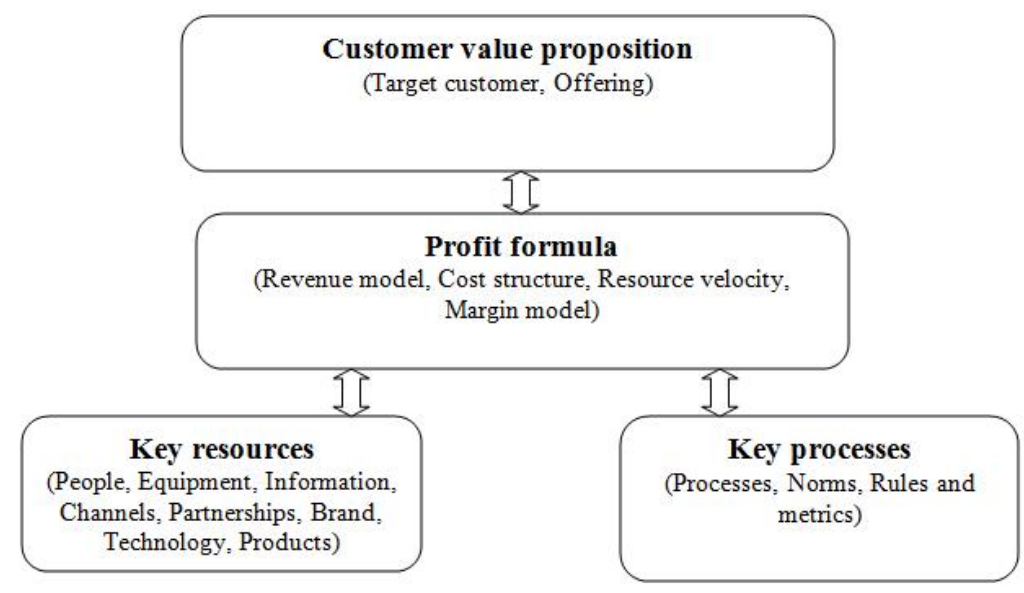

Figure 1: Elements of a successful business model

Source: Johnson et al. (2008).

Further studies looking to conceptualize the elements of a sustainable model have been performed by other authors, such as Stubbs and Cocklin (2008), who emphasize the importance of treating nature like a stakeholder and the necessity of leaving the environment in a better state than the one in which it was found through the minimized use of resources or the recycling of resources. Todd (2009) underlines the struggle of corporations today between maintaining a balance between shareholder value and ensuring environmental quality.

In the renewable energy field, specific business models have emerged besides the traditional energy model. Nasti and Rask (2012) have used the nine building blocks scheme of Osterwalder and Pigneur (2010) and have \adapted it for the renewable energy field, as shown in Figure 2. 


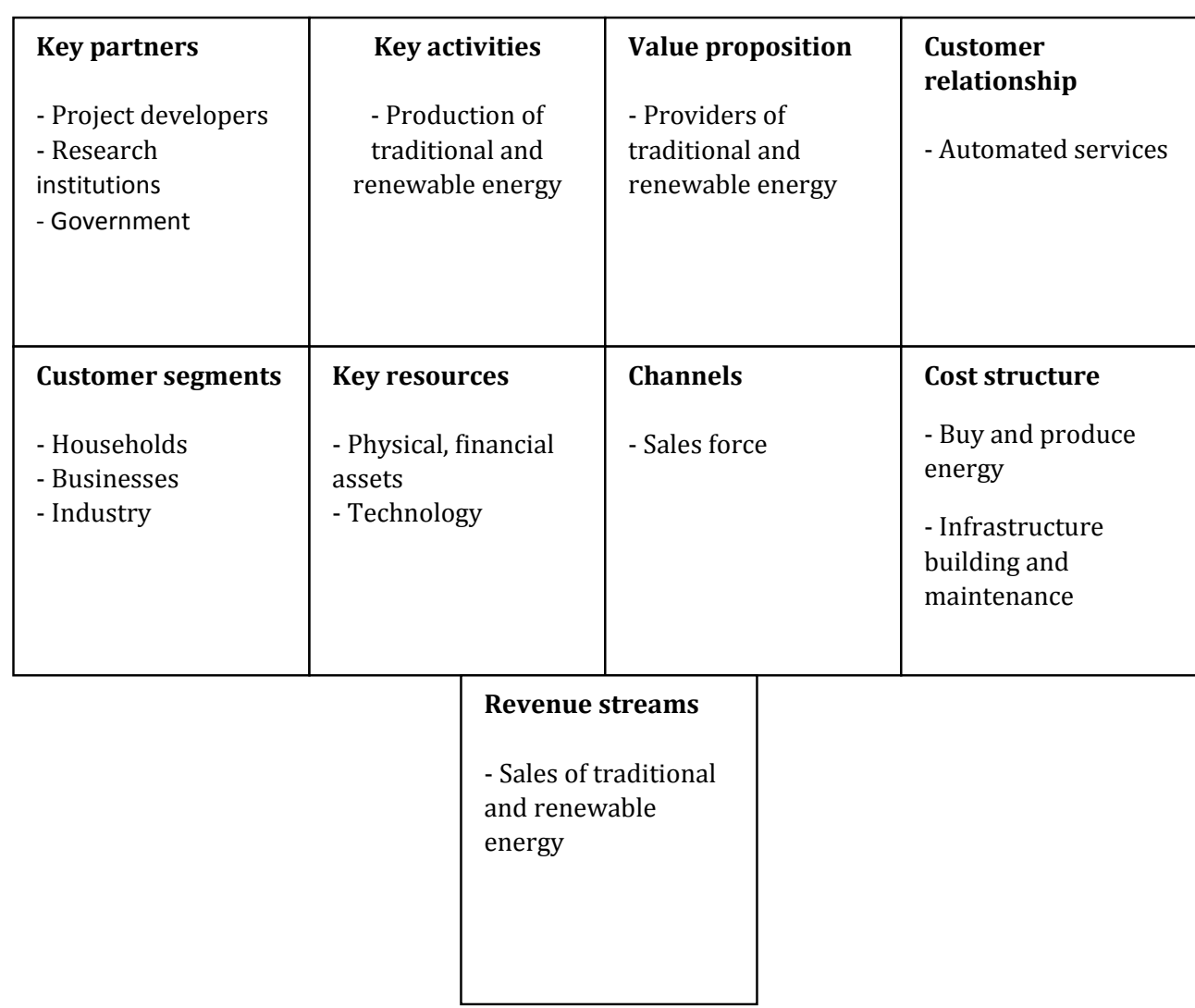

MMCKS

54

Figure 2: Business model scheme applied to the renewable energy field Source: Nasti and Rask (2012).

Richter (2011) classifies the specific business models in the renewable energy fields according to three types of cooperation: cooperation with suppliers, cooperation with development companies and cooperation with other utilities. The first two types of cooperation allow the utility to concentrate on its core activities, while suppliers and development companies manage a part of their business. The cooperation among utilities allows them to develop large projects through the resources invested during the partnership period. In a different study (Richter, 2012), the same author specifies another typology of renewable energy business models that are frequently encountered in the European Union in the current context: the customer-side business model and the utility-side business model. The customer-side business model is practically a direct business between the renewable energy utility and the client. Renewable energy systems are installed on the customer's property by the utility. The utility gains revenues from services offered to the customer and from the return on assets (Frantzis et al., 2008). The customer benefits from the renewable energy assets, which they could hardly afford otherwise. The utility-side business model is used in the case of large projects and is similar to the common energy model. The produced electricity is fed into the grid and there is no direct relationship to the end-customer. Certain studies have researched other elements of sustainable business models in the renewable energy, such as in the case of solar energy, the ownership either by the solar energy company or the local energy supplier and the type of photovoltaic 
MMCKS parks, with implications for the decision making rights, as well as for the revenue sources (Tanțău et al., 2013; Tanțău, 2014).

55

\section{Research methodology}

The purpose of the present article is to offer an overview of the most frequently implemented business models in wind and photovoltaic Romanian energy in 2013, as well as of the estimated future trends until 2020 in the two sectors of research. For this study, the classical form of the Delphi method was used in order to ensure a structured planning of the questioning phases. According to Hiltunen's (2013) Delphi model, the practical part of the present research was divided into ten phases as follows: the selection of the research topic, the questionnaire preparation based on the consultancy of university and renewable energy experts, selection of the participating experts, the first phase of interviews with the experts, the analysis of the results, informing the experts on the obtained results, the second phase of interviews with the experts, the analysis of the results, the interpretation and summary of results, feedback on the experts regarding the final results of the interviews. The research period was extended from the 1st of May 2013 until the 30th of March 2014.

The study was conducted based on a sample of 51 experts from the two fields ( 26 experts in the wind energy field and 25 experts in the solar energy field). There were a total of 22 questions included in the research questionnaires that were offered in the two phases of interviews with the experts. The first phase of interviews inquired in regards to the current wind and solar energy business models. The second phase of interviews referred to the expected future trends of business models in Romania until 2020.

In the first phase of the interviews issues such as the current elements of business models in wind and solar energy were addressed. These elements included the type of wind parks and PV utilities used by the participating companies and strategies to gain revenues and ownership. The second round of interviews focused on the trends expected in business models in the two analyzed sectors such as selling strategies and the perception of the legal environment in Romania as a factor of influence for the investment context of wind and solar companies.

Regarding the size of the experts' companies, the majority of the companies had a maximum of 50 employees; respectively, $46 \%$ of the wind energy companies and $60 \%$ of the solar energy firms. In the case of wind energy companies, a significant rate of large scale firms with more than 1000 employees (19\%) have contributed to the study and $15 \%$ had between 150 and 1000 employees. The rest of the companies had a size of 50-150 employees. In the photovoltaic field, $32 \%$ of the interviewed firms had 50-150 employees and only 2 companies had more than 500 employees.

\section{Findings and analysis}

The most important finding of the study refers to the preferred business model strategies that were similar in the case of wind and solar energy fields. The 
strategy of "selling electricity to a trading company (different than the regional grid operator)" was mentioned by the almost half of the wind energy specialists $(42 \%)$ and photovoltaic energy experts (48\%). The experts chose the alternative of having a trading company as a business partner instead of the regional grid operator due to the flexibility of trading firms to negotiate the electricity price and thus gain a better contract. A second option was the strategy of "selling electricity to the regional grid operator" which was mentioned by $30 \%$ of the wind energy experts and $17 \%$ of the solar energy experts. Furthermore, the wind energy experts affirmed that the wind plant operators also sell green certificates to trading companies $(27 \%)$ and to regional grid operators $(23 \%)$, while the strategy of "selling electricity to a third party consumer" received 19\% of the experts' confirmations. The majority of the interviewed specialists were involved in more than one renewable energy projects and declared that they have used multiple strategies simultaneously.

Another important finding of the study revealed that there are only onshore wind energy plants in Romania and no off-shore wind energy plants due to the lack of convenient climate conditions and cost efficiency. A vast majority of the wind energy experts also stated they owned on grid wind farm turbines (93\%), as shown in Figure 3.

The second part of the interviews revealed that the most popular business model strategy currently implemented in wind and solar energy is also the main estimated future trend until 2020. All experts in the wind energy field described at least two types of business models as future trends. As shown in Figure 4 and Table $1,65 \%$ of wind energy operators and $52 \%$ of photovoltaic energy companies mentioned the trend of selling energy to trading companies as the main strategy until 2020.

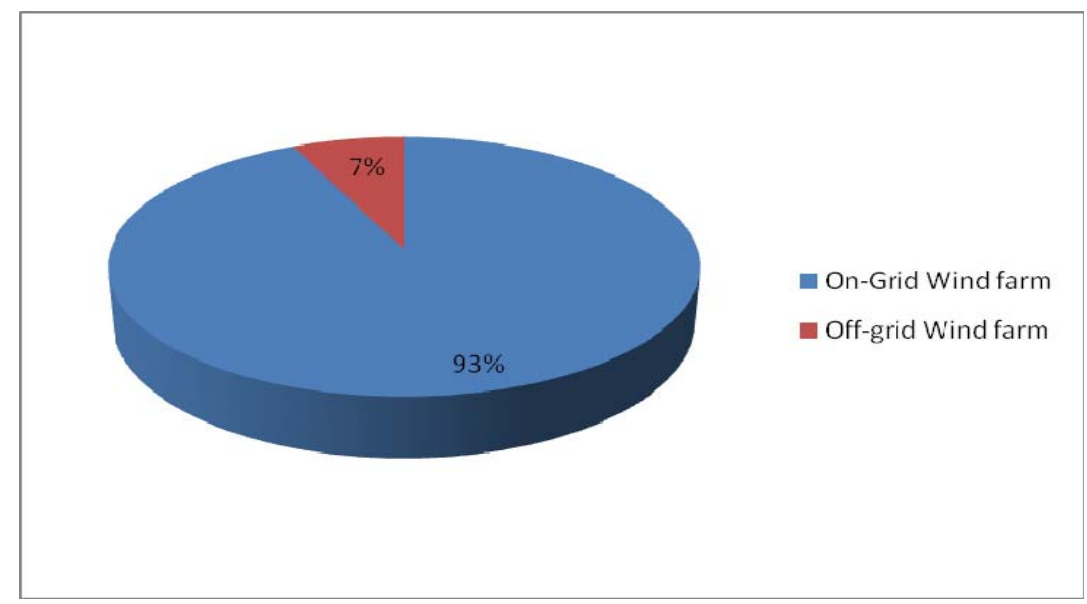

Figure 3: Types of wind farm (turbines) in Romania 2013 as described by the wind energy experts

Source: Author's own research results.

The option of selling energy to the regional grid operator was the second preferred alternative in the current context by wind energy companies (53\%), while the third preference was to sell GCs to the trading companies. 
MMCKS

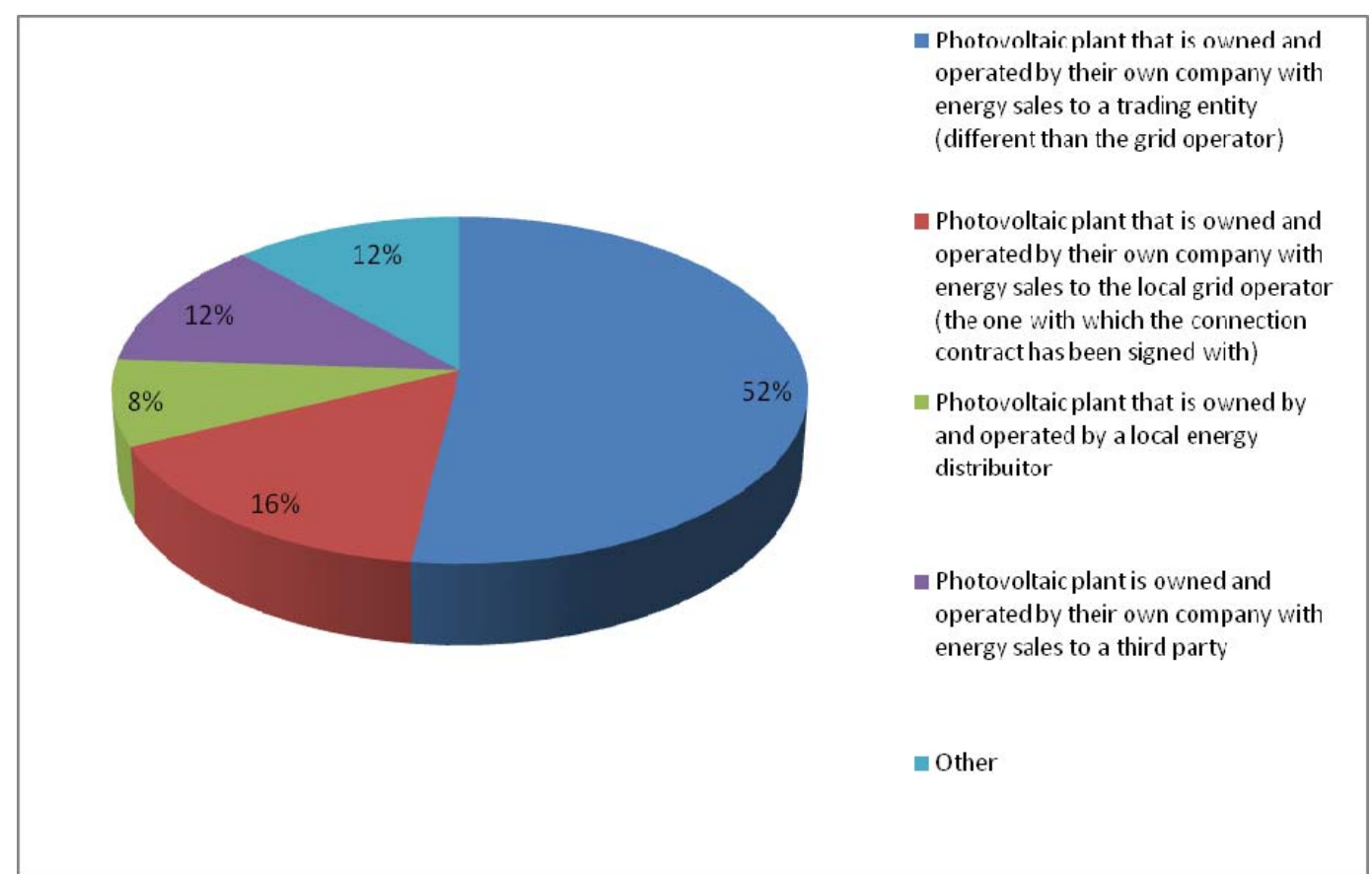

Figure 4: Future trends in business models of photovoltaic energy companies in Romania until 2020

Source: Author's own research results.

An equal share (30\%) of the wind energy experts choices was selling either green certificates to regional grid operators or energy to third party consumers. In the case of solar energy, the second choice of the photovoltaic energy experts was to sell electricity to the local grid operator (16\%), while $12 \%$ stated the PV plant was owned and operated by their company with energy sales to a third party. $8 \%$ of the photovoltaic plants were owned and operated by local energy suppliers. The rest of the respondents mentioned other similar alternatives of photovoltaic plants.

Most of the experts described the future trends in wind energy projects until 2020 as on-shore and on-grid projects. Small-scale projects with a maximum of $10 \mathrm{MW}$ were considered as the most efficient by $48 \%$ of the interviewed specialists. The small-scale projects were described as safer against financial and regulatory risk.

Table 1. Future trends in business models in the wind energy field until 2020

\begin{tabular}{|l|l|}
\hline Wind energy operators will rather use the following strategies until 2020: & \\
\hline -sell electricity to trading companies & $65 \%$ \\
\hline -sell electricity to the regional grid operator & $53 \%$ \\
\hline -sell green certificates (GCs) to trading companies & $38 \%$ \\
\hline -sell electricity to third party consumers & $30 \%$ \\
\hline -sell electricity GCs to regional grid operators & $30 \%$ \\
\hline
\end{tabular}

Source: Author's own research results. 
The last part of the research described the influence of the legal environment in Romania on the two renewable energy fields. A lack of reliability of the Romanian renewable energy environment could be observed and was explained by the experts through the cuts in the support scheme that occured on the 1st of July 2013. There are further concerns regarding the lack of regulatory predictability. $62 \%$ of the wind energy respondents stated that the legal changes in July 2013 reduced the number of projects they were involved in. Additionally, 87\% of the same respondents also described another consequence: stopping their company's ongoing projects. Another $27 \%$ of the companies focused on other countries for future projects. In the photovoltaic field, the majority of the respondents still perceived investment opportunities (65\%) while only $35 \%$ described the field as uncertain and lacking opportunities.

\section{Conclusions}

All three hypothesis of the paper were confirmed by the empirical inquiry. Thus, wind and solar energy companies prefer to sell electricity to a trading company due to the extended price negotiation possibilities which are not provided by the regional grid suppliers. The second assumption that the future trends in wind energy projects until 2020 are expected to be on-shore and on-grid wind farm turbines was also supported by the respondents. The third hypothesis revealed that both wind and solar energy respondents agree on the fact that the strategies of selling electricity to trading companies and to the regional/local grid operators will be the main future trends in the two sectors.

The results of the comparative study of business models in wind and solar energy indicate clear directions for the two fields until 2020. These directions can be justified not only by the internal objectives of the company, but also by the influence of the legal context in Romania. Limitations of the current study include the participating sample of experts; as well as the permanently changing regulatory standards which in turn cause changes in the renewable energy industry. The study can be further expanded through the involvement of more participants from the two sectors of renewable energy, potentially also from different countries in the next years.

Though the last year brought a significant growth of the installed capacities in wind and solar energy in Romania, the changing of the renewable energy supporting scheme on the 1st of July 2013 represented the first barrier towards the expansion of further investments in the field. As a consequence, 2014 is expected to be a year of standstill for the solar energy field and a year of diminished investments in the wind energy field. The future research agenda regarding the business models in wind and solar energy includes the observation of their future development as a result of the internal and external influence factors of the companies, an applicable subject to both scientific and business theory. Romania is currently at a critical point in the field of renewable energy, but it will remain an important actor of the European energy market due to its potential of expanding renewable energy capacities. 


\section{MMCKS Acknowledgements}

This work was cofinanced from the European Social Fund through Sectoral Operational Programme Human Resources Development 2007-2013, project number POSDRU/159/1.5/S/142115 „Performance and excellence in doctoral and postdoctoral research in Romanian economics science domain”.

\section{References}

Baden-Fullen, C., Morgan, M.S. (2010), "Business Models as Models", Long Range Planning, Vol. 43, No. 2-3, pp. 156-171.

Eurostat (2014), "The share of renewables in energy consumption up to $14 \%$ in 2012", available online at: europa.eu/rapid/press-release_STAT-1437_en.pdf, (accessed June 4, 2014).

Frantzis, L., Graham, S., Kartoski, R., Sawyer, H. (2008), "Photovoltaics Business Models", National Renewable Energy Laboratory, available online at: www.nrel.gov /docs/fy08osti/42304.pdf (accessed June 5, 2014).

Hedman, J. and Kalling, T. (2003), "The business model concept: theoretical underpinnings and empirical illustrations", European Journal of Information Systems, Vol. 12, pp. 49-59.

Hiltunen, E. (2013), Foresight and Innovation. How Companies are Coping with the Future, Palgrave Macmillan, Hampshire.

Johnson, M., Christensen, C.M. and Kagermann, H. (2008), "Reinventing Your Business Model", Harvard Business Review, available at: fenix.tecnico.ulisboa.pt/ downloadFile/3779580640683/HBR-ReinventingYour-Business-Model\%20.pdf (accessed June 5, 2014).

Nair, S., Paulose, H., Palacios, M. and Tafur, J. (2013), "Service orientation: effectuating

business model innovation", The Services Industries Journal, Vol. 33, No. 9-10, pp. 958-975.

Nasti, M. and Rask, M. (2012), "How can solar photovoltaic emerge in the Danish energy market?", available online at: pure.au.dk/portal-asb-student/files/ 51440857/Photovoltaic_and_Danish_energy_market_M._Nasti_Master_Thesis. pdf (accessed June 4, 2014).

Osterwalder, A. and Pigneur, Y. (2010), Business Model Generation, John Wiley \& Sons, Hoboken.

Richter, M. (2011),"Mastering the Energy Transition. A Review on Utilities' Business Models for Renewable Energies", available online at: www2.leuphana.de/umanagement/csm/content/nama/download/ download_publikationen/Richter_Mastering_the_Energy_Transition.pd (accessed June 2, 2014).

Richter, M. (2012)," Utilities' business models for renewable energy: A review", Renewable and Sustainable Energy Reviews, Vol. 16, No. 5, pp. 2483-2493.

Stubbs, W. and Cocklin C. (2008), “Conceptualizing a Sustainability Business Model", Organization \& Environment, Vol. 21, No. 2, pp. 103-127.

Tanţău, A.D., Regneală, H. and Coraş, E. (2013), "Managing risks in solar energy business" in: Proceedings of the 6th Edition of the International Conference 
on Small and Medium Sized Enterprises in a Globalised World, Babeş- MMCKS Bolyai University, Romania, 25-28 September 2013.

Tanţău, A.D. (2014), "Strategic Issues in Managing Photovoltaic Business in the 60 Context of the European Union. Case study-Romania", International Journal of Economic Practices and Theories, Vol. 4, No. 5, pp. 647-657.

Todd, P.R. (2009), “Corporate Social Responsibility and Global Standardization:

Sustainable Environmental Management in the Chemical Industry", Management \& Marketing. Challenges for the Knowledge Society, Vol. 4, No. 1, pp. 3-16.

Vives, L. and Svejenova, S. (2011), “To, from and beyond the margins: Business models: towards an integrative framework", Management Research, Vol. 9, No. 3, pp. 230-242. 